\title{
Development of Immunopathobiogenesis on SIRS-Sepsis
}

\author{
A. Guntur Hermawan ${ }^{1}$
}

A

BSTRACT: Over the past decade, sepsis has been diagnosed according to consensus guidelines established in 1991 as an infection in addition to the symptoms of systemic inflammatory response syndrome (SIRS). In addition to the previous criteria, the 2001 conference added several new diagnostic criteria for sepsis. Of particular interest was the inclusion of the biomarkers procalcitonin (PCT) and C-reactive protein (CRP), despite the overall conclusion that it was premature to use biomarkers for sepsis diagnosis. The primary recommendation of the panel was the implementation of the Predisposition, insult Infection, Response, and Organ dysfunction (PIRO).

The immune system has traditionally been devided into innate and adaptive components, each of which has a different role and function in defending the host against infectious agents.

Stimulation of different TLRs induces distinct patterns of gene expression, which not only leads to the activation of innate immunity but also increasing evidence supports an additional critical role for TLRs in orchestrating the development of adaptive immune responses.

The superantigens are able to induce toxic shock syndrome and can sometimes cause multiple organ failure via adaptive immune system. The superantigenic activity of the bacterial exotoxins can be attributed to their ability to cross-link major histocompatibility complex class II molecules on antigen-presenting cells outside the peptide groove with T-cell receptors to form a trimolecular complex. This trimolecular interaction leads to uncontrolled release of a number of proinflammatory cytokines. Proinflammatory cytokines especially IFN- $\gamma$ and TNF$\alpha$, the key cytokines causing toxic shock syndrome.

KEYWORDS: Sepsis • innate immunity $\bullet$ adaptive immunity $\bullet$ Toll-like receptors.

\section{Infection and Inflammation}

Infection is a term to refer to the existence of various germs penetrating to human body. Infection occurs when the germs reproduce and cause the damage on tissue. Infection will cause injury that creates inflammation reaction. Although the inflammation has the same basic process, the intensity and the size will be different, depending on the size of the injury and reaction of the body. Acute inflammation may be limited on the place of the injury or may spread that cause symptom and systemic phenomenon $(1,2)$.

Inflammation is the reaction of vascular tissue to all types of injuries. Inflammation is a reaction of blood vessel, nerves, dilution and body cell on the site of injury. Acute inflammation is initial direct response against the agent causing of injury and most of acute inflammation related to the production and the release of chemical mediator.

Clinical manifestation of systemic inflammation is referred as Systemic Inflammation Response Syndrome (SIRS) (3). It is in accordance to sepsis which is known as SIRS with the suspected of infection (4).

\section{DEFINITION}

Definition for sepsis and organ damaged as well as the guidance of innovative therapy on sepsis is referred to Bone et al (5). Systemic Inflammatory Response Syndrome is a patient condition who has two or more criteria as follows:

1. Temperature $>38^{\circ} \mathrm{C}$ or $<36^{\circ} \mathrm{C}$

2. Heart beat $>90 /$ minute

3. Respiration $>20 /$ minute or $\mathrm{Pa} \mathrm{CO} 2<32 \mathrm{mmHg}$.

4. Leukocyte $>12,000 / \mathrm{mm} 3$ or $>10 \%$ immature cell (band). 
Sepsis is SIRS with identified of infection site (it is determined by the positive culture of the organism from the site of infection). Blood culture does not have to be positive. Even though SIRS, sepsis, and septic shock usually related to bacterial infection, there should not be bacteriemia. Bacteriemia is the presence of viable bacteria in the circulating blood. Bacteriemia usually seen after injury on the surface of mucosa, primarily without identified focus of infection, or frequently being secondary to intravascular or extravascular infection.

Serious sepsis is sepsis that related to organ dysfunction, abnormality of hypoperfusion, or hypotension. The dysfunction of hypoperfusion including (but not limited to):

1. Lactate acidosis

2. Olyguria

3. Or acute change on mental status.

Based on international conference on 2001, there are more additions to previous criteria. Conference of 2001 put several new diagnostic criteria for sepsis. The most important part is by inserting biomarkers those are procalcitonin (PCT) and $\mathrm{C}$ - reactive protein (CRP), as the initial step in sepsis diagnosis. The main recommendation is the implementation system of Predisposition, insult Infection, Response, and Organ dysfunction (PIRO) to determine the maximum medication based on patient characteristic with symptom stratification and individual risk $(6,7)$.

\section{Immunopathogenesis}

\section{INNATE IMMUNITY AND SEPSIS: THE ROLE OF THE PATTERN RECOGNITION RECEPTORS (PPRs)}

Immune system is traditionally divided into innate immune system and adaptive immune system. Each immune system has different function and role in protecting host from infectious agents. Response of innate immunity is programmed as a nonspecific first defense mechanism, which acts as a first response to eliminate pathogen entering the body. To prevent the infectious microorganism from entering the body, innate immune system develops various receptors, which is known as PRRs, which has the capability to recognize specifically the pattern of molecular and pathogen (Pathogen-associated molecular pattern/ PAMPs), so that the innate immune system can distinguish the molecule structure of self and non-self ligand (6).

\section{THE ROLE OF TOLL-LIKE RECEPTOR}

Toll-Like Receptors (TRLs) are involved in the host defense against the invasion of pathogens. They function as main sensor of microbial product and activate the signaling path that induced the expression of immune and proinflammatory genes. Furthermore, TLRs imply to a number of inflammation diseases and immune-system-mediated diseases. Immune system needs the balance condition between activation and inhibition to avoid harmful inflammation response.

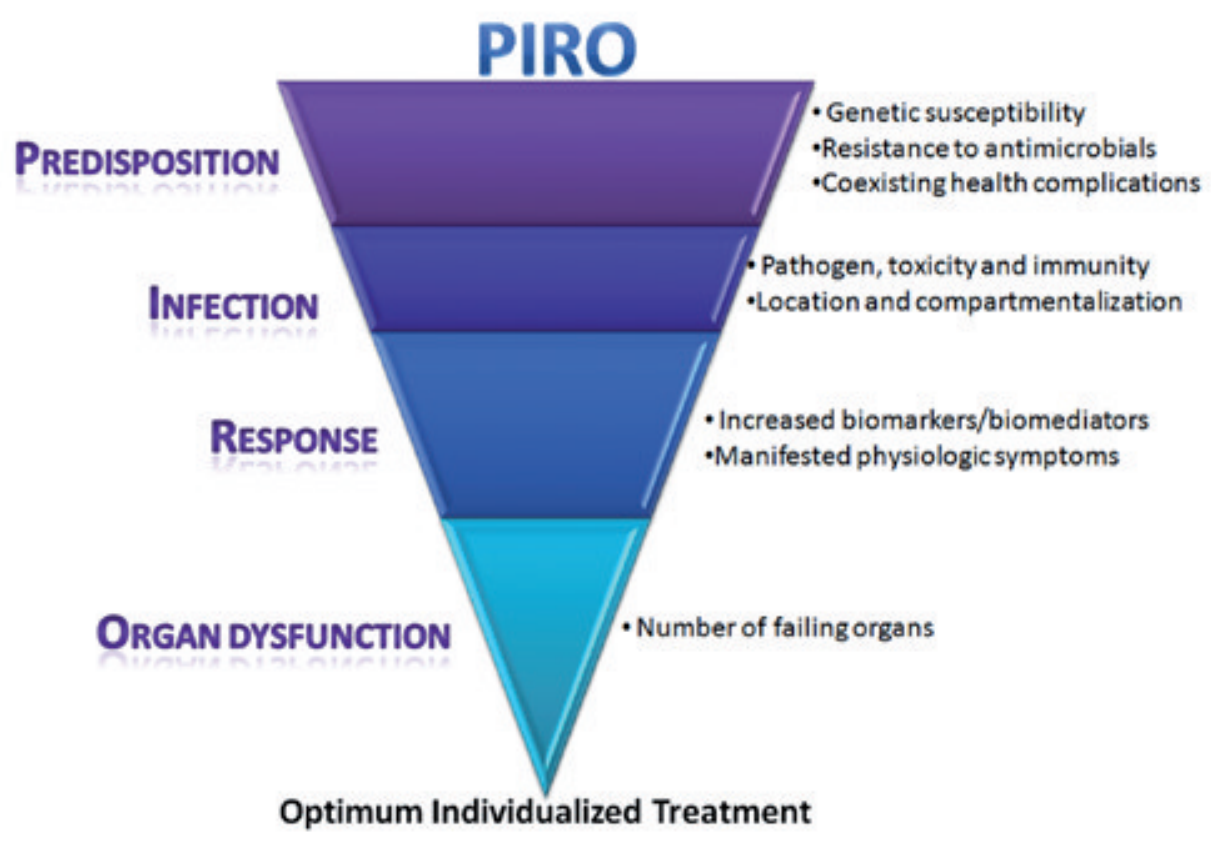

Figure 1. PIRO - directed Treatment Selection on Patient Characteristics (Adapted from Levy MM, et al. 2003) 
TLThaveextracellularegion(containingrepeated leucine) and a cytoplasmic tail, which have a Toll domain/Interleukin-(IL-1 $\quad \beta)(8,9)$. Different TLRs willrecognizethe surfaceand intracellulacomponent of different microorganism.

Interaction between a TLR and a microbial component will activate innate immune system, as well as the adaptive immunity development. TLRs signaling path begins from TIR-domainbecause of recruitment of TIR-Domainwhich contains adaptor, such as MyD88 (myeloid differentiation primaryresponse protein 88 ), TIR $\mathbb{R}$ (TIR-dmain-containing adaptor protein), TRIF (TIR- domain-containing adaptor protein inducing interferon) and TRAM (TRIFrelated adaptormolecule).

Signalthrougheach TLRneeds Myd88to produce inflammatory cytokine. The path of independent Myd88willfollow the signal through TLR $\rightleftharpoons$ or TLR $\square$ to produce interferon. TRIFis important for signal path of TLR and TLR that are Myd88-independent, to produce inflammatory cytokine, which is mediated by TLR4. TRAM is involved specifically on the path of Myd88-independent,which is mediated by TLR $\square$. TIRA mediates path of Myd88-Dependentwhich is mediated by TLR $\square$ and TLR $\square(\square)$.

\section{$\square \mathrm{D} 1 \square \mathrm{A} \square \mathrm{D}$ TLRS}

The specific member of innate immune system includingPRRs(such as $\square$ D1 $\square$ and the TLRs. $\square$ D1 $\square$ is receptor of glycosylphosphatidylinositol $\square \mathrm{kdhat}$ binds LPS with high affinity, and it has an important role in mediatingthe response of Lipopolysaccharide (LPS).The importanceof $\square \mathrm{D} 1 \square$ as a signaltransducer that related to LPS is a result of a genetic study. Ferrero et al showed mouse expresses excessive $\square \mathrm{D} 1 \square$ associated with the hypersensitivityto LPS. $\square$ n the contrary, mouse with CD14 deficiency showed protection against LPS that will induce septic shock.

$\square$ ne of the main progresses in understanding the preliminary recognition on microbe and the development of sepsis is through identification of TLRs.According to Medzhitov et al, TLR indicates the activationof $\square \mathrm{F}-\mathrm{K} \square$ andinduces the expession of a number of pro-inflammatory cytokine as a response to LPS. Recently, additionalhuman TLRshave been found,andnineTLR havebeen characterizedPoltorak et al and $\square$ ureshi et al firstly demonstrated the genetic defect on two mice strains that are hyporesponsive/ nonresponsiveto LPSassociatedwithTLR $\square$ Themore importantthing is they showed a criticalinformation on membranereceptor forLPSby recognizingLPSand bound to the $\square$ D1 andtransducinghe transmembrane signal through TLR $\square$.

In the beginning TLR $\square$ was associated with the signal transducing of LPS, recent genetic studies showed that TLR is the main signal transducerfor LPS. Research using mice with TLR2 deficiency has minimum role on LPS signaling, as the mice are susceptible to the toxic effect of LPS. Anyhow, this study has indicated that TLR (ratherthan TLR $\square$ i) receptor for positive gram organism (such as Staphylococcus aureus and Streptococcus pneumoniae) and its cell wall component, bacteria lipoprotein, and fungus $(1 \square)$.

\section{Superantigen}

Theimmunesystemagainstthe livingor deadbacteria in vivo, has a difference mechanism in releasing TNF- a withrelated to the inductionof gram-negativebacteria and gram-positive bacteria. This difference is similar to the result of the in vitro study. In contrast, in vivo, LPS and lymphotoxinalpha (LTA) showed a similar released kinetics of T $\square$ F- $\alpha$.

The pathogenesis of gram-positive bacteria depend on the level of production of strong exotoxin. Sepsis that is promoted by gram-positivebacteria is differentfrom gram-negative induction.Gram-positive bacteriafre $\square$ uentlycome from skin,wound, soft tissue structure, and location of catheter rather than from enteric resource or genitourinay. In addition, grampositiveorganismneeds a seriesof responsefrom host, with the killing of intracellularby neutrophils and macrophages. This is different from gram-negative pathogen germ, which is ready to be killed in the extracellulamoom by antibody and complement.

$\square$ xotoxinthat is produced by S. aureus and S. pyogenes acts as superantigen bacteria, as protein molecule that is capable to stimulate the T-cell. Superantigencan directly make a bind and stimulate the activation of lymphocyte $\mathrm{T}$ without attributed of macrophages or monocytes as the antigenpresenting cells (AP $\square$ s)Superantigenis knownto be 
able to activate up to $20 \%$ of body lymphocyte and can stimulate the production of various inflammatory mediator, including IL-2, IFN- $\gamma$ and colony stimulating factor (CSF) which in turn stimulate macrophage $(11,12)$. When macrophage is activated, it will secrete not only interleukin-1 but also a series of enzyme (neutral protease, e.g. collagenase and elastase) that is possible to destroy the connective tissue, procoagulant molecule (tissue factor and factor VII) that can cause local coagulation through extrinsic coagulation pathway and plasminogen activator. This elastase enzyme converts plasminogen into plasmin that will damage fibrin and so it will slowly return, and then creates coagulation.

GM-CFS will activate neutrophils and components of C-3, C3R, and C5. Neutrophils will bind to targeted cell i.e. blood vessel endothelia. The function of the blood vessel is then disturbed because of the adherence of neutrophils to the blood vessel endothelia, followed by the blood coagulation due to fibrin deposit. All reactions above are called DTH reaction (13). In addition to the reaction of DTH, IFN- $\gamma$ can also stimulate macrophages to produce IL- $1 \beta$, IL- 6 and TNF- $\alpha$.
These superantigens can also induce toxic shock syndrome and cause multi organ failure (MOF) without any warning. The activity of bacteria exotoxins superantigenic can be linked to its capability to produce cross-link with MHC-II molecules trimolecular complex. Each superantigen is recognized link with specific beta domain from T-cell receptor. The interaction of this trimolecular functions in controlling the releasing number of proinflammation cytokines, especially IFN- $\gamma$ and TNF- $\alpha$, which are the key cytokines in causing the toxic shock syndrome. In addition to those exotoxins harmful mechanism, the gram-positive bacteria contain a number of immunogenic cell wall components, such as LTA and Peptidoglycans (PGNS) (10).

\section{PATHOPHYSIOLOGY OF SEPSIS}

Sepsis is not only caused by gram-negative, but also by gram-positive that produces exotoxin. Exotoxin, virus, and parasite may become superantigens after being phagocyted by monocytes or macrophages as Antigen Processing Cell. This antigen carries specific polypeptide resulting from Major Histocompatibility Complex (MHC). The antigen carrying class II peptide $\mathrm{MCH}$ will bind to CD4+ (lymphocyte Th1 and Th2) under the mediation of TCR (T-Cell Receptor).

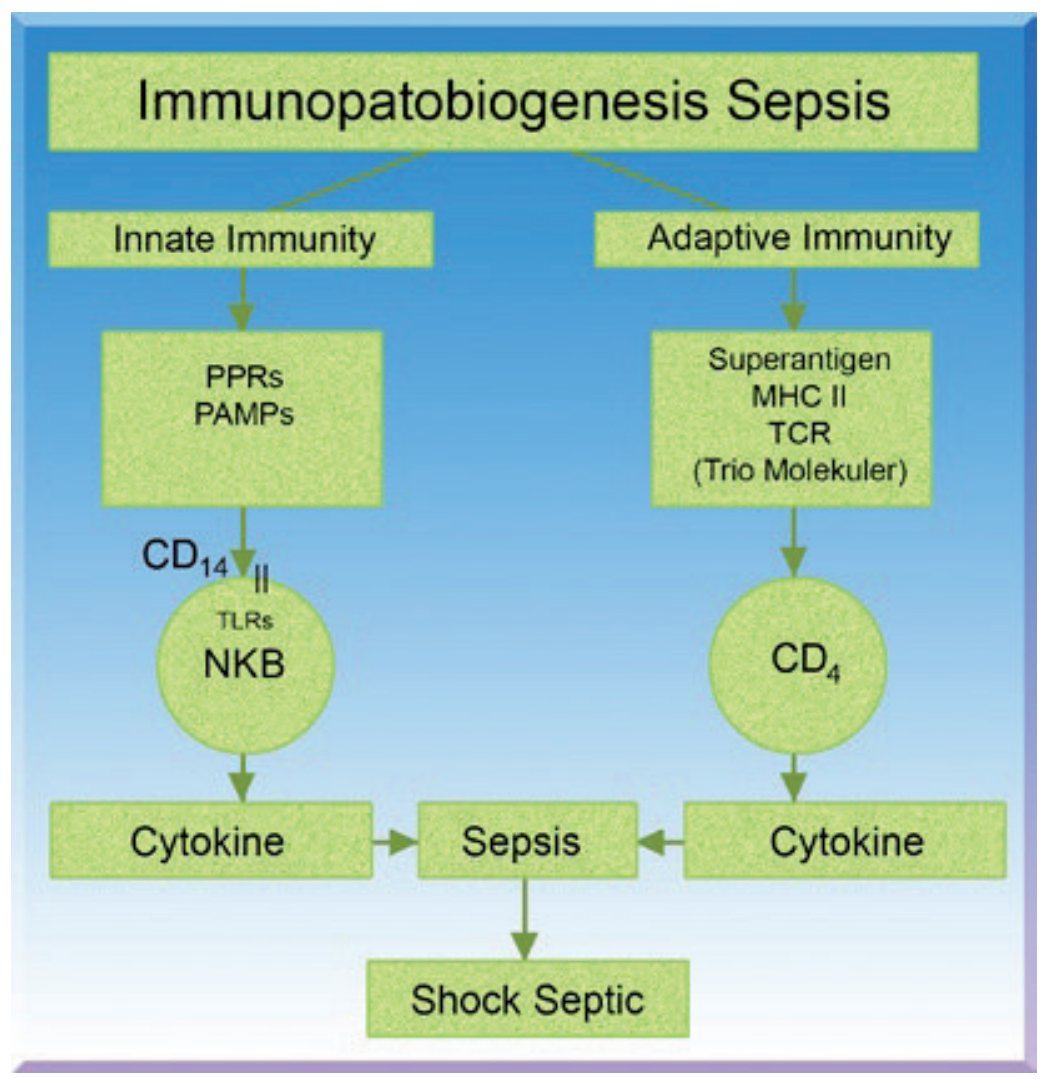

Figure 2. Pathophysiology of Sepsis (Adapted from Guntur, 2005) 
As the effort of the body to react against sepsis, T lymphocyte will secrete substances from $T$ helper 1 (TH1) as immuno modulator, i.e. IFN- $\gamma$, IL-2and MCSF (Macrophage colony stimulating factor) $(12,13)$. Lymphocyte Th2 will express IL-4, IL-5, IL-6 and IL-10. IFN- $\gamma$ will stimulate macrophages to secrete IL-1 $\beta$ and TNF- $\alpha$. IFN- $\gamma$, IL- $1 \beta$ and TNF- $\alpha$ which are proinflammatory cytokine, so that on the sepsis condition there is an increasing level of IL-1 $\beta$ and TNF- $\alpha$ serum. According to several studies, during the occurrences of sepsis, the level of IL- $1 \beta$ and TNF$\alpha$ correlate with the severity of the disease $(4,14)$. However, it appears that cytokine IL-2 and TNF- $\alpha$ not only a response against sepsis, but also it can damage the endothelia of blood vessel of which the cause is still unknown $(15,16,17)$. IL- $1 \beta$ as the main immuno regulator has also impact the endothelia cell, including the formation of prostaglandin E2 (PG-E2) and stimulate the expression of intercellular adhesion molecule-1 (ICAM-1). The presence of ICAM1 causes neutrophils, which has been sensitized by granulocyte-macrophage colony stimulating factor (GM-CSF), more easy to adhere. Interaction between endothelia and neutrophyls consist of three steps, i.e.:

1. The excreted endothelia neutrophyl, P and Eselectin, and L-selectin binding to the respective ligand.

2. The adherence and activation of neutrophile that binds the integrin CD-11 or CD-18, which attach neutrophile onto endothelia with adhesion molecule secreted by endothelia. This step is very important.

3. The transmigration of neutrophile in penetrating the endothelia wall $(4,18)$.

Neutrophyls, which are adhered to endothelia, will secrete lysozyme that will cause lysis to the wall of endothelia, and make the endothelia open. Neutrophyl will also carry superoxidants, which is categorized as free radicals that will influence the oxygenation on mitochondria and GMPs cycle. As the result of the process, endothelia become necrosis (19), which will then cause damage of blood vessel endothelia.
Apparently, the damage of the endothelial blood vessel will cause vascular leak that creates damage on multiple organs. This is in accordance with Bone's opinion that the dysfunction of multiple organ is not caused by infection, rather than as a cause of systemic inflammation with cytokine as mediator (20). The argumentation is supported by Cohen, who stated that the dysfunction of multiple organs is caused by thrombosis and coagulation in small blood vessel which in turn cause septic shock that ends up in death(15).

Septic shock is clinical diagnosis according to sepsis syndrome followed by hypotension (reduced blood pressure $<90 \mathrm{mmHg}$ ) or reduced systolic blood pressure $>40 \mathrm{mmHg}$ from the previous blood pressure. The most significant organs are liver, lungs, and kidney. Mortality rate may increase when dysfunction occurs on those three organs. One study showed that mortality rate of septic shock is of $72 \%$ and $50 \%$ patients died if they had shock more than 72 hours, and of 30\%-80\% patients with septic shock suffer Acute Respiratory Distress Syndrome (ARDS) (21).

According to Dale DC, patients of diabetes mellitus, liver cirrhosis, chronic kidney failure, and elderly age that are of group immuno compromised (IC) are susceptible to sepsis. Heavy complication may frequently occur in IC sepsis patients, such as septic shock and end up in death $(22,23)$. To prevent the occurrence of continual sepsis, th-2 will express IL-10 as antiinflammation cytokine that will inhibit the expression of IFN- $\gamma$, TNF- $\alpha$ and APC mechanism. IL-10 will also repair the damaged tissue caused by inflammation $(24,25)$. Increasing level of IL-10 give the possibility in preventing septic shock in sepsis patients.

\section{THE IMPORTANCE OF CYTOKINE IN SEPSIS}

We observed 22 patients of sepsis and 5 patients of septic shock using cohort method with multivariate analysis from seven variable immune responses: IL-10, TNF- $\alpha$, IL-1 $\beta$, IFN- $\gamma$, IgG, C3, C4. There are significantly different levels between sepsis patients and septic shock patients $(p<0,05)$. The study is followed by discriminant test to find discriminator variable (table 1 and 2): 
Table 1. Multivariate test from septic shock and sepsis patients

\begin{tabular}{|c|r|r|r|r|}
\hline \multicolumn{3}{|c|}{ Septic Shock } & \multicolumn{2}{c|}{ Sepsis } \\
\hline Variable & \multicolumn{1}{|c|}{ Average } & \multicolumn{1}{c|}{ SD } & Average & 9,002 \\
\hline IL-10 & 37,268 & 28,852 & 15,895 & 11,628 \\
\hline IFN- $\gamma$ & 11,204 & 1,557 & 13,164 & 11,927 \\
\hline TNF- $\alpha$ & 35,640 & 13,674 & 19,905 & 3,309 \\
\hline IL-1 $\beta$ & 24,300 & 45,687 & 3,491 & 5,611 \\
\hline IgG & 18,632 & 9,780 & 14,608 & 0,699 \\
\hline C3 & 0,714 & 0,352 & 1,662 & 13,230 \\
\hline C4 & 26,600 & 14,293 & 32,909 & \\
\hline
\end{tabular}

$(p<0,05) ; n=27$

Table 2. Summary of discriminator variable from septic shock and sepsis data, according to the degree of discriminator strenght as shown in Wilks Lambda coefficient.

\begin{tabular}{|c|c|c|c|c|}
\hline Step & Action Entered & Variable in & Wilks Lambda & Sig. \\
\hline 1 I & L-10 & 10 &, 73000 & 0,0055 \\
\hline 2 C & 32 & & 0,53434 & 0,0005 \\
\hline 31 & gG & 30 &, 45169 & 0,0003 \\
\hline $4 I$ & L-1 $\beta$ & 40 &, 36799 & 0,0001 \\
\hline
\end{tabular}

We conclude that the important cytokines in septic shock sepsis are IL-1 $\beta$ and IL-10. On the other hands, the important i mmune r esponses a re I gG humoral response and $\mathrm{C}_{3}$ innate immune system. F rom this data analysis, we suggested there are many mediators from various i mmune s ystems in sepsis and septic shock condition. This condition should be understood to $\mathrm{m}$ ake a $\mathrm{m}$ ore established clinical procedure $\mathrm{f}$ or sepsis and septic shock.
From this study, it was found that the important thing in sepsis is the balance between IL-1 $\beta$ and IL10. If IL-1 $\beta$ is dominant, it will stimulate endothelia to increase PGE-2, PAI-1, and ICAM-1. The increase of ICAM-1 will attract macrophages and neutrophyl into endothelial cells. The adhesive neutrophyl will release lysozyms excretion, which damages the cell wall, and produces superoxides that damages genes, and lead to a death. A series role of IL-1 $\beta$ will cause septic shock with DTH (Delayed Type Hypersensitivy) process. 
If IL-10 is dominant, it will accelerate the maturity of B-cell. It will then differentiate to become plasma cell, and produces IgG. IgG has an effective opsonin characteristic. Together with phagocyte cell, monocytes and macrophage, as well as NK cell will bind tightly through Fc receptor, which will then create damage on the cell wall of blood vessel with antibody dependent cellular cytotoxity (ADCC) process (11). The increase of $\mathrm{C} 3$ in this condition may be the result of $t$ oxin activation. $\mathrm{C} 3$ will $\mathrm{f}$ orm $\mathrm{C} 3 \mathrm{~b}$ that $\mathrm{c}$ an a ccelerate the heavy a mplification process from alternative path (it is e stimated that one deposited $\mathrm{C} 3 \mathrm{~b}$ in a n organism can increase to four millions in four m inutes). $\mathrm{T}$ his will i ntensify the i ncrease of $\mathrm{C} 3$ level. $\mathrm{C} 3 \mathrm{c}$ onsists of $t$ wo particles, $i$.e. C $3 a$ and $C 3 b$. C $3 a$ has the characteristic of anaphylatoxin that can cause blood vessel dilatation, so that the resistance will decrease and the permeability of the blood vessel will increase, and cause plasma extravasation. C $3 \mathrm{~b}$ w ill adhere to targeted cell wall and form unstable bind of protein binding m embrane $w$ ith I gG. It $\mathrm{f}$ orms opsonization through cell $\mathrm{K}$ effector and cause lysis from cell with the process of ADCC (26). The result of this process is decreasing of blood pressure and shock. The damage of blood vessel endothelia is caused not only by DTH, but also by ADCC process (11).

\section{BASIC CONCEPT OF SEPSIS}

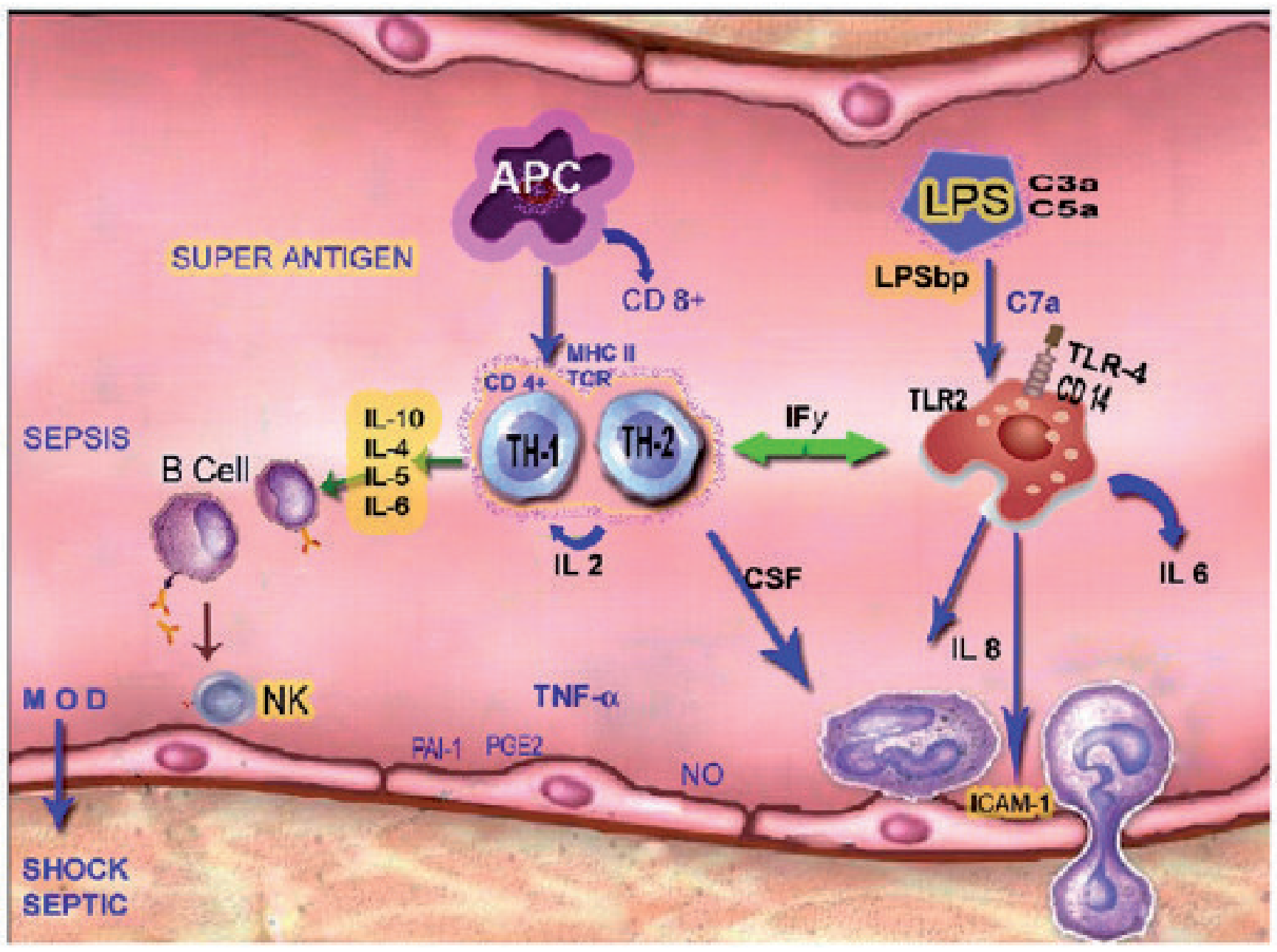

Figure 3. Basic Concept of Sepsis (Adapted from Guntur, 2000) 


\section{References:}

1. Jawetz E, Melnick J, and Adelberg E. Review of Medical Microbiology. 14. 1997.

2. Cotran RS, Kumar V, and Collins T. Pathologic Basic of Disease. WB Saunders Co. London Toronto. 1999. 6th edition.

3. Whitnack E. Sepsis in Mechanisme of Microbial Disease. Williams \& Wilkins. 1993. 2nd edition. 770-778.

4. Thijs LG. Introduction To Mediators Of Sepsis. 5th Symposium On Shock \& Critical Care. 1998. 67-70.

5. Bone RC, Balk RA, Cerra FB, Dellinger RP. Fein AM, Kraus WA, et al. Definitions for sepsis and organ failure and guidelines for the use of innovative therapies in sepsis. The ACCP/SCCM Consensus Conference Committee. American College of Chest Physicians/Society of Critical Care Medicine. Chest. 1992; 101:1644-1655.

6. Carrigan SD, Scott G, and Tabrizian M. Toward Resolving the Challenges of Sepsis Diagnosis. Clinical Chemistry. 2004. 50(8):1301-1314.

7. Levy MM, Fink MP, Marshall JC, Abraham E, Angus D, Cook D, et al. 2001 SCCM/ESICM/ACCP/ATS/SIS International Sepsis Definitions Conference. Crit Care Med. 2003. 31:1560-1567.

8. Liew FY, XV D, and Brint EK. Negative Regulator of Toll-like Receptor-Mediated Immune Response. Nat Rev Immunol 2005; 5:446-458

9. Akira S. \& Takeda K. Toll-Like Receptor Signalling. Nature Reviews Immunology 4, 2004; 499 -511.

10. Van Amersfoort ES, Van Berkel TJC, and Kuiper J. Receptors, Mediator, and Mechanisms Involved in Bacterial Sepsis and Setic Shock. Clin Microbiol Rev. 2003; 16 (3): 379-414

11. Guntur, Perbedaan Respon Imun yang Berperan pada Sepsis dan Syok Septik . Disertasi. 2001; UNAIR. Surabaya.

12. Hamblin AS. Cytokines in pathology and therapy. Citokines And Citokines Receptor. 1993. 65-75.

13. Hoeprich MC, Miyajima A, and Coffman R. Cytokines Paul Fundamental Immunology. 1994. 3th edition. 763-790.
14. Srikadan S, and Cohen J, 1995. The Pathogenesis of Septic Shock. Journal of Infection, 1995; 30: 201-206.

15. Cohen J. Sepsis Syndrom. Journal of Med Int. Infection. 1996. 31-34.

16. Bone RC. The Pathogenesis of Sepsis. Ann intern Med. 1991. 115: 68-457.

17. Werdan K, and Pilz G. Supplement immunoglobulin in sepsis : a critical apprasial. Clin Exp Immunol. 1996.104: 83-90.

18. Israel LG, Israel ED. Neutrophil function mechanism hematology. 1997. 2nd edition. 121-123.

19. Unenue ER. Macrophages, Antigen ñ Presenting Cell and the Phenomena of Antigen Handling and Presentation. In Fundamental Immunology. Raven Press. 1993. 3rd edition. 111-118.

20. Knuefermann $P$, Nemoto $S$, Baumgarten G, Misra A, Sivasubramanaian N, Carabello BA, et al. Cardiac Inflammation and Innate Immunity in Septic Shock. Chest. 2002; 121(4); 1329-1336

21. Barron RL. Patophysiology of Septic Shock and Implications for Therapy. Clinical Pharmacy. 1993.12: 829-845.

22. Yoshida M. Human response in Endotoxemia, endotoxin Pathophysiology and Clinical Aspects. One Day Symposium on Endotoxin. Jakarta. 1994. 7-10.

23. Dale DC. Septic Shock. In Horison $\square$ sText Book of Internal Medicine. 1995. 232-238.

24. Belanti J. Immunologi III. Yogyakarta. Gadjah Mada University Press. 1993. 443-448.

25. Muraille E and Leo O. Resiviting the Th1 / Th2 Paradigm. Scandinavian Journal of Immunology. Instistute of immunology and Rheumatology Norway. 1997; 1-6.

26. Abbas AK. Cells and of The Immune System. Short course Human Immunology, 1994; 25 ñ29. 